\title{
A construção de um projeto de educação antirracista na Educação Infantil em uma EMEF: relatos de experiências e primeiros movimentos
}

Alexandra da Silva Padilha* Jacqueline Zilberstein**

\begin{abstract}
Resumo:
Este trabalho apresenta o relato do processo de construção de um projeto de educação antirracista na Educação Infantil e explicita a necessidade do mesmo, através de relatos de experiência de situações racistas vivenciadas no espaço escolar. O projeto tem por objetivo implementar, de maneira efetiva e contínua, a educação antirracista a partir da Educação Infantil em uma Escola Municipal de Ensino Fundamental (EMEF) da Rede Municipal de Ensino da cidade de Porto Alegre (RMEPOA) no bairro Restinga e se ampara na Lei 11.645/08. Iniciamos com algumas práticas a partir da metade do ano de 2020, tais como a contação de histórias com protagonistas negros, a divulgação de um painel elaborado pelo grupo intitulado Tornando-se antirracista, entre outros, pelas quais buscamos iniciar o despertar das crianças e das famílias para a temática do racismo. Procuramos assim nos desconstruir e reconstruir como professoras e pessoas antirracistas para informar e transformar através da educação.
\end{abstract}

\section{Palavras-chave:}

Educação Infantil. Educação antirracista. Racismo. Projeto Pedagógico.

\begin{abstract}
:
This paper presents the report of the process of construction of an anti-racist education project in early childhood education and explains the need for it, through experience reports of racist situations experienced in the school space. The project aims to implement anti-racist education from early childhood education in a Municipal Elementary School of the city of Porto Alegre in the Restinga neighborhood and is supported by Law $11.645 / 08$. We started with some practices from the middle of 2020 , such as storytelling with black protagonists, the dissemination of a panel prepared by the group entitled Becoming anti-racist, among others, by which we seek to start the awakening of children and families to the theme of racism. We thus seek to deconstruct and reconstruct ourselves as teachers and anti-racist people to inform and transform through education.
\end{abstract}

\section{Keywords:}

Early Childhood Education. Anti-racist education. Racism. Pedagogical Project.

\footnotetext{
* Pedagoga e especialista em Educação Infantil pela UFRGS; professora da Educação Infantil da Secretaria Municipal de Educação de Porto Alegre. E-mail: padilhaalexandra71@gmail.com. ORCID iD: https://orcid.org/0000-0002-4911-5373.

** Mestra em Ciências do Movimento Humano pela UFRGS; professora de Educação Física da Secretaria Municipal de Educação de Porto Alegre. E-mail: jacquezilberstein@hotmail.com. ORCID iD: https://orcid.org/0000-0002-9646-6264.
} 


\section{Introdução}

O racismo é uma questão estrutural (ALMEIDA, 2019) e a escola, enquanto instituição que faz parte de tal estrutura, pode contribuir para a perpetuação ou modificação da sociedade. Segundo o artigo $2^{\circ}$ da Lei de Diretrizes e Base da Educação Nacional (LDBEN) (BRASIL, 1996), "[a] educação, dever da família e do Estado, inspirada nos princípios de liberdade e nos ideais de solidariedade humana, tem por finalidade o pleno desenvolvimento do educando, seu preparo para o exercício da cidadania e sua qualificação para o trabalho". Partindo desse entendimento, este relato ilustra o processo de construção de um projeto para a educação antirracista e as experiências de situações racistas vivenciadas por duas professoras no espaço escolar que, entre outros, motivaram a realização do mesmo. Este não é apenas um projeto para a escola, mas um propósito de vida.

Esse projeto objetiva implementar a educação antirracista a partir da Educação Infantil em uma Escola Municipal de Ensino Fundamental (EMEF) da Rede Municipal de Ensino da cidade de Porto Alegre (RMEPOA) no bairro Restinga. Este projeto se ampara na Lei no 11.645 (BRASIL, 2008), que torna obrigatório o estudo da história e cultura afro-brasileira e indígena no currículo escolar. Pretende-se que a educação antirracista seja trabalhada na escola para além das atividades desenvolvidas na semana da consciência negra e se torne realmente parte do currículo dessa escola de maneira transversal. Tendo a Educação Infantil como contexto de desenvolvimento do projeto, entendemos ser importante trazer alguns apontamentos sobre esse nível de ensino.

A história da Educação Infantil é bastante recente em comparação ao Ensino Fundamental, visto que as instituições pré-escolares foram difundidas internacionalmente a partir da metade do século XIX (KUHLMANN JR., 1998). Inicialmente, de acordo com Kuhlmann Jr. (1998), os espaços pré-escolares foram criados com uma concepção assistencialista, de maneira que as mães trabalhadoras pobres tivessem um local para deixar seus filhos. Esses espaços tinham como principal objetivo o cuidado - cuidado com a alimentação e higiene - enquanto as famílias permaneciam fora, no trabalho. O primeiro movimento legal, no que diz respeito à garantia de direitos, ocorre após muitas lutas de movimentos sociais ligados à mulher, à infância e reivindicações da sociedade civil brasileira, com a Constituição Federal de 1988 (BRASIL, 2020), onde a criança é definida pela primeira vez como sujeito de direitos. O próximo movimento legal ocorre em 1996 com a LDBEN (BRASIL, 1996), onde inclui a Educação Infantil como primeira etapa da Educação Básica. Diante de tal determinação, as crianças de 0 a 5 anos passam a ter direito à educação formal por meio do ensino em instituições próprias integrantes do sistema de ensino. A criança pequena passa a ser vista como um sujeito em desenvolvimento que tem suas especificidades. Atualmente, o que norteia as aprendizagens essenciais no Ensino Básico é a Base Nacional Curricular Comum (BNCC).

De acordo com a BNCC (BRASIL, 2017), a criança pequena, aluna da Educação Infantil, deve ser compreendida como um sujeito histórico que é constituída a partir do contexto que a cerca e das experiências pelas quais vivencia. Essa criança é observadora, questionadora, cria suposições, julga e constitui seus valores de forma autônoma e protagonista por meio da interação cultural.

Ainda de acordo com a BNCC (BRASIL, 2017), a Educação Infantil é composta por dois eixos estruturantes da prática pedagógica - interações e brincadeiras - e prevê seis direitos de aprendizagem e desenvolvimento para as crianças: conviver, brincar, participar ativamente, explorar, expressar, conhecer-se. O documento também propõe que as aprendizagens das crianças sejam estabelecidas em acordo com os seguintes campos de experiência: eu, o outro e o nós; corpo, gestos e movimentos; traços, sons, cores e formas; escuta, fala, pensamento e imaginação; espaços, tempos, quantidades, relações e transformações. A definição e a denominação dos campos de experiência são baseadas nas Diretrizes Curriculares Nacionais para a Educação Infantil (BRASIL, 2010) e devem ser incluídos nas metodologias dos(as) professores(as) em sala de aula.

O grupo que pensou tal projeto é constituído por professores negros e não negros atuantes na Educação Infantil de uma EMEF da RMEPOA localizada no bairro Restinga. O primeiro movimento desses professores foi reconhecerem-se enquanto racistas e, a partir disso, buscam se desconstruir e reconstruir 
para além dos portões da escola. A partir de tal processo, entendemos que alunos negros e não negros têm o direito a uma educação antirracista e que é necessário que a branquitude reconheça seus privilégios e, com isso, a autoria do racismo.

A branquitude é um lugar de privilégios que colabora para uma sociedade desigual, preconceituosa e racista. Não é um poder dado, natural, é um exercício de dominação cotidiana. E, sendo assim, circula por todas as estruturas da sociedade. Segundo Cardoso e Müller (2017, p. 23),

[a] branquitude significa pertença étnico-racial atribuída ao branco. Podemos entendê-la como o lugar mais elevado da hierarquia racial, um poder de classificar os outros como não brancos, que, dessa forma, significa ser menos do que ele. O ser branco se expressa na corporeidade, a brancura. E vai além do fenótipo. Ser branco consiste em ser proprietário de privilégios raciais simbólicos e materiais.

O racismo foi muito bem pensado e estruturado e, por isso, está em todas as instituições. Em nosso país, é encontrado de forma diferenciada dos demais devido à sua sutileza. Segundo exposto por Kabengele Munanga em uma entrevista concedida à revista Fórum no ano de 2012, "[e]le é velado. Pelo fato de ser sutil e velado isso não quer dizer que faça menos vítimas do que aquele que é aberto. Faz vítimas de qualquer maneira" (RAMOS; FARIA, 2012).

Tal fato deve-se ao discurso de mestiçagem que é muito forte no Brasil, no qual o discurso do "somos todos iguais" ainda reverbera. Pretendemos apresentar às crianças a história do continente africano, suas diferentes culturas, nossos heróis negros, como foi o processo de escravização e o porquê a partir daí foram, e ainda hoje são, necessárias várias lutas e discussões sobre o racismo.

\section{Relatos de experiências sobre o racismo na instituição escolar}

Diante do apresentado, eu, Alexandra, trago meus relatos de experiência enquanto professora e supervisora negra na Educação Infantil.

Em meados de 1997, trabalhei em um centro infanto-juvenil conhecido no bairro Restinga em Porto Alegre enquanto ainda cursava pedagogia. $\mathrm{O}$ centro atendia crianças e adolescentes carentes do bairro no contraturno e algumas crianças permaneciam no centro em torno de $10 \mathrm{~h}$ por dia, fazendo as três refeições no mesmo. Designaram-me a trabalhar com uma turma de Jardim B - na creche de turno integral que havia dentro deste centro - constituída por 25 alunos na faixa etária entre 5 a 6 anos de idade. Cabe ressaltar que a maioria das crianças atendidas nesse local eram negras.

Como de costume, após o lanche levei as crianças à pracinha para que pudessem brincar. O pátio onde se encontrava essa pracinha era bem grande e as educadoras tinham de se dividir para ter uma visão melhor das crianças. Neste dia, ouvi um barulho de alvoroço das crianças nos fundos da escola e corri para ver o que acontecia. Para minha surpresa, uma aluna negra (para a qual vou dar o nome fictício de Emily) estava amarrada em uma das vigas de madeira do centro e era, literalmente, chicoteada com os casacos dos colegas enquanto os mesmos gritavam "toma nega fedorenta". Lembro de meu desespero ao ver aquela cena tão chocante. Gritei, ordenei que parassem e desamarrei a menina que chorava compulsivamente. Perguntei àquelas crianças qual era a razão para tudo aquilo? Qual a razão para tamanha violência contra uma colega? Eles, talvez por perceberem minha revolta, ou pela vergonha, ou até mesmo por medo, não conseguiram me responder. Resolvi, então, chamar a coordenadora pedagógica (não negra) do centro para conversar com as crianças, visto que eu não acreditava ter subsídios para uma intervenção pedagógica eficaz naquele momento.

Para minha surpresa, a coordenadora entrou na sala, fez uma rodinha com as crianças - sob minha atenta observação -, colocou a menina no centro da roda, virou-se para as crianças e as questionou: "Vocês bateram na Emily porque ela é pobre? Porque ela é preta? Porque ela é suja?". A cada pergunta feita pela coordenadora a menina ia se curvando, se encolhendo, chorando. Por fim ela arrematou dizendo "Ela é 
preta, suja, mas vocês têm que ver que ela é gente!”. Neste instante, abri a porta da minha sala, sentei na rua e chorei. Chorei por ela e chorei por mim, porque aquela criança havia apanhado pela segunda vez na escola. Naquele momento descobri que se fazia necessária uma educação antirracista na Educação Infantil. Já em 2017, aos 16 anos de experiência como docente da RMEPOA, assumi o cargo de supervisora da Educação Infantil em uma EMEF no bairro Restinga. No setor de Serviço de Orientação Pedagógica (SOP) e Serviço de Orientação Educacional (SOE) da escola recebemos, entre outras situações, alunos com dificuldades comportamentais. Por diversas vezes, recebemos também alunos(as) que sofrem racismo através de xingamentos dos colegas. Esses xingamentos passam (em sua maioria) desapercebidos pelos professores que minimizam a situação. As meninas negras são as que mais conseguem chegar ao SOP/SOE, com as reclamações dos insultos racistas geralmente referindo-se a cor da pele e ao cabelo: "nega micoca", "nega macaca", “cabelo de Bombril”. Já os meninos negros são encaminhados ao SOP/SOE em grande parte por terem agredido fisicamente outro colega. Após algum tempo de conversa acabamos descobrindo que a agressão física foi a reação a outra agressão, a verbal, pois são ofendidos igualmente como às meninas negras. Dou destaque a um acontecimento, ocorrido numa manhã na escola.

Os alunos atrasados aguardavam no saguão da escola o sinal do segundo período para que pudessem ingressar à mesma, seguindo as normas daquela instituição. Dentre os atrasados estava Jorge (nome fictício), único aluno negro naquele espaço naquele momento. A patrulha escolar da brigada militar, como de costume, estacionou o carro em frente ao portão. Um policial militar desceu do veículo e imediatamente dirigiu-se a Jorge. O policial começou a interpelar o adolescente questionando sobre sua presença no local. O aluno, visivelmente contrariado, respondeu de maneira ríspida "Pergunta pra sora ali o que eu tô fazendo aqui", apontando para a vice-diretora que passava pelo pátio do lado de dentro da escola. O policial continuou com a abordagem truculenta dizendo que o menino estaria faltando com o respeito a uma autoridade. Jorge questionou: “Por que só eu? E se tu quer respeito, te dá o respeito!". Isso ocorreu sob a observação da vice-diretora que concordou plenamente com a abordagem, visto que se tratava de um aluno que costumava frequentar bastante o SOP/SOE da escola por questões comportamentais. O policial levou o aluno para a frente da escola e, com truculência e anuência da direção da escola, o revistou. Como se não bastasse, o aluno ainda foi conduzido ao SOP/SOE onde lá continuou sendo tratado como infrator. A vice-diretora e o policial repetiam que ele era um "desaforado e desrespeitoso" e que teriam que chamar a família. Neste momento tomei ciência do que estava acontecendo e fiquei revoltada. Não entrei na reunião, mas chamei a outra vice-diretora (a direção era composta por duas vice-diretoras e uma diretora) e falei que aquela era uma situação claramente racista. Qual não foi minha surpresa à resposta da segunda vice-diretora, que disse “Alexandra se trata do Jorge! Aluno terrível, sem respeito. Ele mereceu!". Revidei dizendo que naquela situação ele estava certo, pois só ele havia sido abordado e que estava no espaço escolar, deveria ser protegido por nós visto que não estava oferecendo risco, a escola não havia chamado a brigada e não havia situação de perigo algum para que ele fosse abordado daquela maneira. Foi então que ela me respondeu: "Acho que tu tem que te acalmar, tu está com tua negritude muito aflorada". Naquele momento, assim como Jorge, fui ferida, agredida. Só pedi que a mesma se retirasse de minha sala para eu não fazer como o aluno.

A família do aluno foi chamada à escola e não fui convidada a fazer parte dessa reunião - acredito que pelo fato de eu ser a supervisora da Educação Infantil ou por ter a negritude sempre muito aflorada. Contudo, fiquei em minha sala ao lado e tomei conhecimento do diálogo entre o familiar (na figura do padrasto), a diretora e o policial. Pude perceber o silêncio de Jorge. O padrasto nos trouxe a informação de que o adolescente trabalhava em uma lancheria no período da noite, como chapista, e chegava em casa por volta das duas horas da manhã. Por conta disso tinha dificuldade em acordar cedo para ir à escola. Fui informada que o padrasto ainda colocou que ele e a mãe de Jorge prezavam pelo respeito e que não admitiriam essa postura do aluno. Toda a conversa foi conduzida para que Jorge fosse silenciado, e ainda, obrigado a pedir desculpas ao policial. Ao cruzar a sala percebi que Jorge estava cabisbaixo, chateado e certo de que estava certo. Talvez, por já compreender, inconscientemente, como funciona o racismo em suas estruturas e zelando pelo bem de seu enteado, o padrasto tenha obrigado o menino a pedir desculpas. Minha inação me causou extrema dor e desconforto. Depois que todos se foram, chamei o aluno, dei um abraço nele e sussurrei “Continua sempre na luta pelos teus direitos!”. Ele me olhou, sorriu e seguiu para sua sala de aula. 
Agora eu, Jacqueline, apresento meu relato de experiência enquanto professora de Educação Física não negra na Educação Infantil. Narro duas situações que me marcaram com alunas de 5 anos que se subjugavam por conta do racismo.

A primeira experiência ocorreu em uma turma de atividade extracurricular com crianças de uma escola da rede privada da cidade de Porto Alegre no bairro Santa Cecília, ainda durante minha graduação no ano de 2012. Eu buscava as alunas em suas salas e, enquanto aguardava, ficava observando seus desenhos nas paredes do corredor. Um dia notei que a única aluna negra da turma (tanto da regular quanto da minha) - a qual irei chamar pelo nome fictício de Ana - desenhava-se com cabelos loiros e com lápis de cor rosado, chamado na época de "cor de pele". Questionei a professora referência sobre os desenhos dela e a mesma me relatou que Ana sempre se desenhava dessa forma. Comentei também que ela não gostava que mexessem em seus cabelos, pois antes de minhas aulas eu amarrava os cabelos de todas para que não se machucassem e perguntei se ela notava isso em sala. A professora contou que durante uma brincadeira de cabeleireira, na vez de Ana ser a "cliente", a colega que mexia em seus cabelos disse que ele parecia ser de plástico e essa afirmação deixou a menina muito triste e constrangida.

Ana ia embora de transporte escolar e, por não ter contato com a família, comentei com o motorista do transporte sobre a situação com a qual me deparei e ele disse que iria repassar à família. Na semana seguinte, Ana havia tirado as tranças, alisado os cabelos e estava muito feliz e confiante com o novo cabelo. Nesse mesmo dia, a mãe da aluna foi buscá-la para falar comigo e disse não ter notado a questão dos desenhos e que não percebia sofrimento da filha até o dia em que ela chegou em casa chorando, dizendo que não queria ter o "cabelo de plástico". Pediu que eu a ajudasse nesse processo de fortalecimento da autoestima de Ana, pois apesar dela fazer isso em casa e achar que seria suficiente, percebeu que a filha sofria ao não encontrar referências naquela instituição, por estar fora do "padrão".

A minha segunda experiência foi já enquanto docente da RMEPOA no ano de 2017 em uma EMEF no bairro Restinga com uma turma de Jardim B. A escola estava construindo um painel de fotos para decorar o saguão durante o sábado letivo da Consciência Negra com todos os alunos que se autodeclaravam negros e eu me dispus a fazer as fotos dos alunos da Educação Infantil. Entrei na sala da turma, expliquei a proposta da atividade às crianças, conversamos sobre o que era se autodeclarar e, enquanto fazia a chamada, questionava as crianças como elas se autodeclaravam. As que se autodeclaravam negras tiravam a foto e as que se autodeclaravam brancas, não. Como o critério adotado pela escola foi o citado anteriormente, as crianças brancas que se autodeclaravam negras foram fotografadas - e foram várias. No entanto, quando chamei uma menina - de fenótipo negro e pele clara - e ela se declarou branca, um colega interveio dizendo “Não, tu é preta. Pretinha que nem eu!”. A menina começou a chorar com a intervenção do colega dizendo que era branca, pois sua mãe era branca e seu pai negro, então ela era branca. O colega ficou chateado com a reação da menina e por deixá-la triste. Ele ainda tentou explicar à colega que ser negro não era algo negativo dizendo, “Mas não tem problema ser preto! Eu sou lindo!”. Com auxílio da turma, retomei com a aluna sobre seu fenótipo, sobre sua família e ao final da conversa ela pareceu concordar que era negra, que isso não era algo ruim e quis tirar a foto. Percebi o quão despreparada eu estava para lidar com aquela situação e que necessitava buscar formação.

\section{Primeiros movimentos na construção de um projeto de ERER na Educação Infantil}

Ao relatarmos nossas experiências com o racismo em sala de aula, ilustramos a importância dos objetivos específicos pensados para o nosso projeto, que são os seguintes: a) instrumentalizar a comunidade escolar, a partir da Educação Infantil, sobre questões referentes à educação antirracista; b) efetivar a utilização de materiais didáticos que cumpram as determinações legais sobre história e cultura afro-brasileira; c) incentivar a utilização de materiais didáticos produzidos por pessoas negras; d) desenvolver o estranhamento (de alunos, professores e da comunidade escolar) de falas e práticas racistas que nos permeiam; 
e) reconhecer e respeitar a diversidade como algo intrínseco a vida em sociedade; f) estimular a empatia/ alteridade para com o próximo; g) fortalecer a autoestima dos alunos a partir do conhecimento da história e cultura afro-brasileira; h) desconstruir estereótipos de beleza impostos por uma sociedade de colonização europeia; i) conscientizar pessoas não-negras sobre a necessidade de sua atuação como sujeitos antirracistas.

Ao longo da construção do esqueleto desse projeto, percebemos que não existe educação antirracista na escola sem o envolvimento de toda a comunidade escolar e que para isso a metodologia deveria envolver esse universo - pais, alunos, professores e funcionários. Assim sendo, dividimos as possibilidades metodológicas em dois eixos: formação de professores e intervenções didático-pedagógicas. No eixo da formação (continuada) de professores, através de um grupo de estudos sobre Educação para as Relações Étnico Raciais (ERER), iremos propor leituras e debates sobre possibilidades de implementações didáticas em nosso fazer pedagógico. Já no eixo de intervenções didático-pedagógicas buscaremos promover com os demais integrantes da comunidade escolar (por meio de atividades lúdicas, contação de histórias, jogos, brincadeiras, desenhos, vídeos, rodas de conversa, entre outros) o ensino da história afro-brasileira (diáspora), explicando aos alunos como era a vida das pessoas escravizadas antes de chegarem ao Brasil, como foram trazidas e como isso reflete nas relações étnico-raciais atualmente; o conhecimento das diversas culturas (corporais, de movimento, religiosas, éticas, filosóficas, entre outras) africanas e afro-brasileiras; o reconhecimento das diversas formas de conhecimento para além do acadêmico - como, por exemplo, o dos griôs -; a visibilidade de pessoas negras em diferentes empregos, promovendo assim a representatividade dessas pessoas aos alunos em vista de ampliar suas perspectivas quanto à diversas possibilidades.

\section{Considerações finais}

O projeto vem sendo estruturado a partir da nossa construção como agentes transformadoras da realidade e em meio a um período de pandemia. Ao nos deparamos com o distanciamento obrigatório da prática docente e com as incertezas sobre como ou quando a retornaríamos a escola, optamos por manter algumas rotinas no intuito de não perdermos o vínculo com os alunos e nem a prática de nosso ofício. Enviamos, pela página do Facebook da escola, vídeos de contações de histórias e brincadeiras às crianças de forma a manter o vínculo com eles e com suas famílias, tendo em vista que a paralização das aulas ocorreu durante o período de adaptação dos mesmos. Conseguimos também estabelecer reuniões semanais com todos os professores que atuam na Educação Infantil - algo que durante a rotina escolar era praticamente impossível. Após a notícia do assassinato de George Floyd, iniciamos uma reunião comentando o fato de como esse caso era possível ainda nos dias de hoje. O racismo - antes pouco mais velado - estava sendo praticado de maneira ostensiva, sem qualquer preocupação com as consequências que tal ato poderia acarretar. Analisamos que essa prática estava presente em todos os espaços, inclusive na escola, e que já havíamos presenciado/vivenciado situações em que o racismo se fazia presente. Assim, nos motivamos a pensar um projeto que buscasse erradicar o racismo por meio da Educação.

Começamos com a nossa própria formação sobre a temática, para nos apropriarmos com maior elucidação sobre o que gostaríamos de propor com tal projeto. Iniciamos com a leitura do Pequeno manual antirracista de Djamila Ribeiro (2019), no intuito de nos localizarmos no debate. Após a leitura e discussão desta obra, lemos O que é lugar de fala? também de Djamila Ribeiro (2012) e um relato de experiência intitulado “Professora, ainda posso mudar de cor?': As crianças pequenas e suas impressões sobre as relações raciais na escola” de Míghian Danae Ferreira Nunes ${ }^{1}$, buscando assim compreender que lugares ocupamos na luta antirracista e como as crianças nos mostram as marcas que o racismo imprime nelas, por vezes de maneira subliminar e por outras de forma explícita.

1. Texto produzido durante o curso "Educação, Relações Raciais e Direitos Humanos", oferecido pela Ação Educativa no ano de 2012. Disponível em: http://livrozilla.com/doc/320496/. Acesso em: 14 ago. 2020. 
Realizamos algumas práticas a partir da metade do ano de 2020 (como a contação de histórias com protagonistas negros, a divulgação de um painel elaborado por este grupo intitulado Tornando-se antirracista, entre outros), pelas quais buscamos iniciar o despertar das crianças e das famílias para a temática do racismo. O caminho é longo, urgente e possível. Seguimos nos formando como professoras e pessoas para informar e transformar através da educação.

\section{Referências}

ALMEIDA, Silvio Luiz de. Racismo Estrutural. São Paulo: Pólen, 2019.

BRASIL. [Constituição (1988)]. Constituição da República Federativa do Brasil. Brasília, DF: Presidência da República, [2020].

BRASIL. Ministério da Educação. Base Nacional Comum Curricular: educação é a base. Brasília, DF: MEC, 2017.

BRASIL. Ministério da Educação. Diretrizes curriculares nacionais para a educação infantil. Brasília, DF: MEC/SEB, 2010.

BRASIL. Lei no 9.394, de 20 de dezembro de 1996. Estabelece as diretrizes e bases da educação nacional. Diário Oficial da União: seção 1, Brasília, DF, p. 27.833, 23 dez. 1996.Disponível em: http://www.planalto.gov.br/ccivil_03/leis/19394. htm. Acesso em: 14 jul. 2020.

BRASIL. Lei $\mathrm{n}^{\circ}$ 11.645, de 10 março de 2008. Altera a Lei no 9.394, de 20 de dezembro de 1996, modificada pela Lei $\mathrm{n}^{\circ}$ 10.639, de 9 de janeiro de 2003, que estabelece as diretrizes e bases da educação nacional, para incluir no currículo oficial da rede de ensino a obrigatoriedade da temática "História e Cultura Afro-Brasileira e Indígena". Diário Oficial da União: seção 1, Brasília, DF, p. 1, 11 mar. 2008. Disponível em: http://www.planalto.gov.br/ccivil_03/_ato20072010/2008/lei/l11645.htm. Acesso em: 14 jul. 2020.

CARDOSO, Lourenço; MÜLLER, Tânia Mara Pedroso. Branquitude: estudos sobre a identidade branca no Brasil. São Paulo: Appris, 2017.

KUHLMANN JR., Moysés. Infância e Educação Infantil: uma abordagem histórica. Porto Alegre: Mediação, 1998.

RAMOS, Camila Souza; FARIA, Glauco. Nosso racismo é um crime perfeito. Fórum, Porto Alegre, 9 fev. 2012. Disponível em: https://revistaforum.com.br/revista/77/nosso-racismo-e-um-crime-perfeito/. Acesso em: 14 ago. 2020.

RIBEIRO, Djamila. Pequeno manual antirracista. São Paulo: Companhia das Letras, 2019.

RIBEIRO, Djamila. O que é lugar de fala? Belo Horizonte: Letramento: Justificando, 2017.

Data de submissão: 16/08/2020

Data de aceite: $27 / 09 / 2020$ 